\title{
Un acercamiento al comportamiento del precio de los esclavos en La Habana en la segunda mitad del siglo XVI
}

\author{
Marcos D. Arriaga Mesa \\ Universidad del País Vasco, Vitoria-Gasteiz
}

En el presente artículo se aborda el comportamiento del precio de la fuerza de trabajo esclava en La Habana de la segunda mitad del siglo XVI, teniendo en cuenta aspectos tales como la edad, el sexo y la procedencia de los esclavos. Asimismo se atiende al tema de la compraventa de esclavos conocedores de un oficio, que estuvo relacionado con la práctica, extendida por la Ciudad, de alquilar esclavos. Las fuentes del mismo son fundamentalmente las escrituras notariales de la ciudad de La Habana surgidas entre los años 1578 y 1600, que me posibilitaron la conformación de una muestra que ha sido sometida al análisis estadístico matemático. Igualmente fueron consultadas las actas del Cabildo de la Ciudad propias de ese periodo y gran parte de los documentos relacionados con el quehacer cubano de esos años que se conservan en el Archivo General de Indias en Sevilla. El análisis particular del fenómeno de la compraventa de esclavos en La Habana, nos ha permitido arribar a conclusiones que matizan los criterios anteriormente establecidos sobre el comportamiento de este mercado en la mencionada ciudad.

\section{Introducción}

Según la estimación de la Casa de la Contratación de Sevilla, en el último cuarto del siglo XVI los esclavos eran considerados como la mercancía más importante que se llevaba a América. ${ }^{1}$ La Habana no se mantuvo ajena a ese proceso de introducción y comercialización de esclavos y es por ello que cualquier estudio de la actividad comercial de esta ciudad en la segunda mitad del siglo XVI, no deba ni pueda obviar el análisis del fenómeno de la compraventa de esclavos en esos años.

La incipiente sociedad habanera de mediados y fines de los quinientos, se encontraba en un proceso de afianzamiento de su base económica y la mano de obra esclava jugó un papel importante en este proceso de búsqueda y ubicación del "rol cubano" en el sistema económico metrópoli-colonias, un rol que le permitiera recuperarse del estancamiento en que le dejó el abandono provocado por la minería continental y además desarrollar deter-

1 Serrera, Ramón María: "La organización de las Indias." Historia de España. Descubrimiento, colonización y emancipación de América. Madrid, 1990, T. VIII, cap. 3, pág. 204. 
minados cultivos, crías y producciones artesanales, que lograran satisfacer la demanda de los habitantes de la Ciudad y que a la vez posibilitaran la incorporación de algunos productos al comercio "exterior" de la época.

Ya en la segunda mitad del siglo, con el papel dado al puerto habanero en la Carrera de Indias y la consiguiente conversión de la Ciudad en un más fuerte mercado, se produjo un aumento súbito de la demanda de productos de la tierra; con esto la tenencia de mano de obra esclava se hizo una necesidad imperiosa, que los habitantes de La Habana buscaron resolver por todos los medios.

Se plantea que la presencia de esclavos africanos en Cuba estuvo estrechamente vinculada a la producción azucarera, no obstante es bien sabido que casi desde los inicios de la colonización de la Isla, estuvo presente el esclavo africano como mano de obra en la minería, en algunos cultivos de subsistencia, en la construcción de las fortificaciones y en el cumplimiento de las labores domésticas.

La historiografía cubana más reciente que trata el tema, plantea una división en cuanto a los tipos de esclavitud existentes en la historia de Cuba. Una primera que denominan patriarcal, utilizando el término explicado por Marx, y otra de plantación, en la que la masa esclava es explotada principalmente en los latifundios cañeros con el fin de producir para el mercado capitalista. Esta tipificación señala como fundamental en el siglo XIX — para ser más exactos desde los últimos años del siglo XVIII- la esclavitud de plantación, mientras que denota el predominio de la patriarcal en los siglos XVI, XVII y XVIII. ${ }^{2}$

Como es sabido, todas las operaciones de compraventa que se realizaban en La Habana debían registrarse en alguna de las escribanías existentes en aquel entonces. Lamentablemente a nuestros días sólo ha llegado parte de las escrituras de la denominada Escribanía de Antonio Regueyra, donde oficiaron algunos de los principales escribanos de la época, tales como Juan Bautista Guilisasti y Martín Calvo de la Puerta. ${ }^{3}$ Los documentos de esta escribanía datan desde el año 1578 y el número de escrituras referidas a compras de esclavos entre ese año y 1600 - muchas de ellas incompletas, truncas o totalmente destruidas- está cercano a los 900.

Es por ello que el estudio de la compra y venta de esclavos en la segunda mitad del siglo XVI en La Habana, debe necesariamente circunscribirse

2 Torres Cuevas, Eduardo y Reyes, Eusebio: Esclavitud y sociedad. Documentos para la historia de la esclavitud negra en Cuba. La Habana, 1986, págs. 11-12.

3 Esta escribanía lleva el nombre de su último propietario en el siglo XIX. 
a los años que median entre 1578 y 1600, teniendo en cuenta además como un factor contrario al interés cognoscitivo, el hecho de que aún en el período señalado, faltan escrituras de los años que van del 1580 al 1584 y también de 1594; además hay escasa información de algunos otros.

El tipo de fuente también nos plantea la típica pregunta sobre la representatividad y suficiencia de estas escrituras, y nos pone ante la dificultad de que nos resulta imposible realizar constataciones ya que en la actualidad carecemos de cifras exactas sobre población, llegadas de barcos negreros, etc. que serían fundamentales para realizar un control de proporciones.

Todo ello, lógicamente, nos hace conscientes desde un primer momento de que las respuestas de nuestras interrogantes nunca podrán tener un carácter generalizador y definitivo. No obstante, los datos existentes pueden ser analizados cualitativa y cuantitativamente y el carácter repetitivo y típico de estas escrituras permite arribar a conclusiones referentes al comportamiento de los precios en el período en general y en cada uno de los años en particular.

La compraventa de esclavos en La Habana del siglo XVI no ha sido profundamente tratada. Algunos autores contemporáneos han tenido en cuenta este aspecto en obras de mayor amplitud temática, pero pocos han contado con la revisión de los protocolos para la confección de sus trabajos, debido principalmente al carácter inédito de estos documentos y a las dificultades de su consulta por las características de su escritura y por su deterioro.

Es por ello que continúa sin elaborarse un estudio analítico del comportamiento de los precios de la mano de obra esclava, un estudio que tome en cuenta la influencia ejercida en estos precios por las características de "la pieza", determinando la posible correlación entre el precio y algunos de estos rasgos fundamentales del esclavo. Nuestro trabajo centra su objetivo en estudiar los aspectos anteriormente señalados.

\section{Ideas generales y presentación de una muestra}

Con la revisión de las fuentes notariales se detectó un total de 880 operaciones de compraventa, con un número de 1.138 esclavos vendidos. Una vez desechados 88 casos, se conformó una población de 1.050 individuos con información referente a cinco variables, a saber: fecha de la operación, sexo, edad del esclavo, procedencia geográfica o étnica del mismo y el precio.

La muestra general se subdividió a su vez en varias muestras según los parámetros de la población que se pretendía estudiar, para de esta forma 
caracterizar la población masculina y femenina, caracterizar las distintas representaciones según su procedencia étnica o geográfica, analizar la población según grupos de edad, evaluar el comportamiento de los precios por cada año y para todo el período.

En el año 1556, por una real cédula del 6 de junio, la Corona fija en 100 ducados el precio de los esclavos que se vendían en Cuba, ${ }^{4}$ pero a los pocos años, en 1561, otra real disposición deroga la anterior en tanto que iba directamente en contra del proceso introductor de mano de obra esclava en el Nuevo Continente y afectaba todo intento productivo en la Isla.

Se plantea que los precios de los esclavos variaban según la edad y la salud de los mismos, que también podía influir en ellos la condición de bozal o ladino de "la pieza", su carácter y sobre todo si conocían un oficio. Esto último estaba muy relacionado con el alquiler de esta mano de obra, algo que se fue generalizando en La Habana y que reportaba al dueño considerables ganancias, y también con la costumbre, prohibida por varias ordenanzas, de mandar a los esclavos a ganar de por sí.

Un esclavo se encarecía además por el pago a la Corona de los impuestos propios del comercio de la época - almojarifazgo, avería, lonja- y por el precio de la concesión del asiento. A estos valores se sumaban los gastos de fletamiento y mantenimiento de la carga en el océano.

Datos encontrados en los registros de la Casa nos hacen pensar que, en la década del 90, los pagos que se debían hacer para introducir esclavos en Cuba variaron, no en gran medida pero sí en una cantidad de ducados considerable, lo que lógicamente se reflejó en el precio final del esclavo con un encarecimiento paulatino del mismo.

La ley establecía la prohibición de vender esclavos a un mayor precio del que se les había dado en el momento de su introducción en América; con esto se perseguía impedir la especulación con el traspaso de los esclavos de un propietario a otro. Según el historiador Ramiro Guerra, esta disposición iba en perjuicio del comprador de un bozal, quien al comprarlo no tenía garantizada la adaptación del mismo y además debía adiestrarlo en el trabajo, y lógicamente al venderlo más adelante por la misma cantidad, sufría pérdida. ${ }^{5}$

Con la revisión de las fuentes no detectamos ni un solo caso de esclavo bozal acabado de introducir y vuelto a vender más adelante a un mayor

4 Archivo General de Indias (AGI), Justicia, 1154, r. 1, n. ${ }^{\circ}$.

5 Guerra y Sánchez, Ramiro: Manual de historia de Cuba. La Habana, 1938, págs. 84-85. 
precio. La muestra que hemos manejado evidencia en unos pocos casos la reventa de esclavos a precios mayores que los de su compra. Tratando de ahondar en este aspecto, hemos seguido las compraventas de esclavos de armazones realizadas por los principales mercaderes que actuaron en la ciudad y no hemos podido hallar un solo caso de reventa de un esclavo a un mayor precio, lo cual resulta paradójico, pues significaría que estos comerciantes venderían los esclavos sin obtener ganancia alguna.

Pensamos que debieron existir determinados subterfugios ilegales, mediante los cuales los mercaderes pudieron lucrarse con este tipo de operación, ya fuera cambiando el nombre del esclavo, realizando la reventa en otra escribanía o incluso llevándolos a vender en otras poblaciones; ahora bien, nuestras fuentes no revelan estos manejos.

Como ocurría con todo tipo de mercancía, en el mercado de esclavos también primó la forma de pago fraccionada, en la que posiblemente estuviera escondido además un tanto por ciento de interés. Las características propias del mercado habanero de limitación de compradores y recursos monetarios y amplia arribada súbita de productos, en este caso esclavos, provocaban una necesidad de venta a plazos, pues los compradores no contaban con las cantidades pedidas y los vendedores se veían obligados a aceptar adelantos, fianzas e hipotecas de pago, que en la mayoría de los casos tardaban años en cumplimentarse.

En la mayor parte de los casos se hipotecaban los propios esclavos comprados; también en otros tipos de operaciones mercantiles aparecían los esclavos, como garantías de pago por la compra de pipas de vino y de harina, de piezas de cuero y de ganado. ${ }^{6}$ Incluso mediaron los esclavos como valor en operaciones de préstamo monetario y de empeño. ${ }^{7}$

6 Son muchos los ejemplos de estos casos en la documentación y por ello brindamos aquí la referencia de algunos ejemplos escogidos al azar:

-Rojas, María T. de: Índice y extractos del Archivo de protocolos de La Habana. La Habana, 1947, T. I, pág. 64, 16 de marzo de 1579: Hipoteca de una esclava por deuda de 100 ducados resto del pago de dos pipas de vino. Ibídem, págs. 79-80, 23 de abril de 1579: Hipoteca de un esclavo por pago de 120 cueros de toros.

-Archivo Nacional de Cuba (ANC), Escribanía de Antonio Regueyra, 1591, fols. 130v-131v. 18 de mayo de 1591: Hipoteca de dos esclavos por pago de una pipa de vino del Aljarafe. Ibídem, 1592, fols. 368v-370r. 4 de junio de 1592: Hipoteca de una esclava junto con una casa, por pago de tres pipas de vino de Castilla. Ibídem, 1595, fols. 282r-283r. 1 de marzo de 1595: Hipoteca de una esclava por pago de 68 arrobas y 15 lbs. de harina. Ibídem, 1597, fols. 429v-430r. 3 de noviembre de 1597: Hipoteca de una esclava por pago de cinco pipas de harina.

7 Ibídem, 1587, fols. 577r-578r. El 13 de enero de 1587 Diego de Mesa se obliga a pagar a Diego de Miranda 24 ducados que le prestó, y para seguridad hipoteca una esclava biáfara de 20 años, que por supuesto tenía un valor muy superior a 24 ducados en ese momento. 
Los esclavos recién llegados en cargazones tenían por lo regular un precio menor que los demás esclavos vendidos en la ciudad; en ello influía el estado de depauperación en el que arribaban, luego de viajar hacinados en los barcos negreros.

Una de las cartas dirigidas por los oficiales reales a Felipe II en agosto de 1572, relacionada con la llegada de 193 de los 300 esclavos que designó fueran a Cuba por su orden, nos da una pauta del deplorable estado en que llegaban:

“... pusímoslos en la estancia de La Chorrera donde se han reformado y hoy comienzan a trabajar los 110 varones y así harán los demás a fin de este mes, hanse muerto tres y una niña de enfermedad de cámaras tenemos gran cuenta de curarlos y así están fuera de peligro y van convaleciendo." ${ }^{8}$

Pero no sólo murieron esos cuatro casos citados anteriormente, sino que para el mes siguiente ya habían fallecido trece a causa de la viruela, además de otros once esclavos que no vinieron en esa cargazón, pero que fueron contagiados. Es decir, que luego de dos meses de haber llegado aún estaban "convaleciendo", no en balde tenían que tener los recién llegados un precio bastante inferior, ya que no estaba totalmente garantizada su supervivencia.

Esto se aprecia claramente al comparar los precios de ambos tipos de esclavos; en los recién llegados se observan generalmente precios inferiores al promedio calculado para los años en que se vendieron, lo cual es tan evidente, que en 1596 y 1600, años en que se comerciaron las "piezas" de las armazones de Leonardo Flores y Gonzalo Prieto, el precio promedio de los esclavos es inferior al de los años inmediatos. (Ver apéndice 1).

Esto estuvo motivado principalmente por los menores precios de los esclavos de cargazón, mas que por cualquier otra causa relacionada con la oferta-demanda, pues se sabe que en el período la oferta de esclavos no llegó a satisfacer en ningún momento la necesidad de la población de estas fuerzas, sino que por el contrario se solicitaba al rey autorización para introducir nuevas cantidades, a pesar de que no se contaba en muchos momentos con el dinero preciso para el pago de los esclavos llegados.

No obstante, también era posible vender esclavos recién llegados a precios más elevados, lógicamente en estos casos la salud del cautivo no se había resquebrajado tanto como la de la mayoría de sus compañeros de viaje; es así como se dieron ventas de algunos de la mencionada cargazón, tan-

8 AGI, Santo Domingo, 1122, libro 5. 
to hombres como mujeres, en cifras de hasta 220 ducados. Pero eso sí, jamás los precios de los esclavos acabados de llegar se aproximaron a los precios máximos anuales de la década del 90, que oscilaron entre los 300 y los 400 ducados.

Cabe la posibilidad de pensar que en determinados casos influyera también en el precio de los esclavos el que fueran vendidos en grupos, es decir que fueran comprados en lote y con ello se abaratara el precio de cada uno. Situaciones que puedan indicar este procedimiento no abundan en las fuentes; se pudo apreciar en nuestro estudio que en las ventas de grupos de esclavos el precio individual era igual e incluso en algunos casos mayor que el precio promedio de la "pieza de esclavo".

Debemos agregar que prevaleció, a lo largo de todo el período analizado, la compraventa de esclavos de forma individual, aunque se observan en la muestra una cantidad de operaciones de compra de más de un esclavo por un solo individuo (95 operaciones que representan el 10'79\%), principalmente en parejas, (un total de 66 operaciones); también se llegaron a vender excepcionalmente en grupos de 3, 4, 5, 6, 7 y hasta 12 esclavos, este último caso es una compra realizada por Daniel Baez de Araujo a Cosme Luys, el 2 de agosto de $1596 .{ }^{9}$

De lo anterior se desprende que existió una correspondencia biunívoca entre el número de operaciones efectuadas y la cantidad de esclavos vendidos, es decir a mayor número de operaciones realizadas en un año corresponde una mayor cantidad de esclavos vendidos y viceversa.

En relación con el total de operaciones de compraventa de esclavos realizadas anualmente, en nuestra muestra se aprecia un aumento paulatino de la cantidad de compraventas y del número de esclavos vendidos. Sin dejar de tener en cuenta el deterioro de las escrituras y la desaparición de un numeroso grupo de ellas, se hace evidente que en los primeros años, en los que la llegada de esclavos a la Ciudad era más esporádica y menos cuantiosa, la cantidad de operaciones fue mucho menor que las realizadas a partir de 1595 , en los que a causa de la política de asientos, al florecimiento de determinadas producciones y al aumento de la población en La Habana, la llegada de esclavos se hizo más regular y cuantiosa. (Ver el apéndice 1).

En los años 1597 y 1598 se aprecia un descenso de la cantidad de operaciones y por ende del número de esclavos vendidos (86 operaciones con 42 esclavos y 65 con 71 esclavos respectivamente).

9 ANC, Regueyra, 1596, fols. 476r-478v. 
Los bajos niveles de venta registrados en estos últimos años pudieran deberse a la escasez de datos en las fuentes, pero debemos tener también en cuenta los altibajos sufridos por la llegada a La Habana de embarcaciones, en enormes cantidades en 1595 y 1596, luego en cuantía mediocre en 1597 y 1598 y con un considerable ascenso en 1599 y $1600 .{ }^{10}$

\section{La influencia de la edad en el precio de los esclavos}

Los esclavistas calculaban la edad de los esclavos por estimación visual que se expresaba habitualmente en las escrituras por un intervalo numérico, por ejemplo, "entre 15 y 16 años", "entre 21 y 25 años".

Alerta el doctor Fraginals sobre el margen de error que introduce esta estimación, pero alega como un factor de confianza en los datos, la amplia experiencia de los esclavistas en este asunto, quienes se basaban en la práctica sistemática en el mercado de esclavos. ${ }^{11}$

Se hace evidente que el grueso de las piezas que se comerciaron en el mercado habanero se hallaban en las edades de mayores posibilidades para la producción, lo cual influye en el precio de la forma siguiente: se nota un aumento del precio del esclavo hasta los 30 años y un descenso a partir de los 35 años aproximadamente.

Los grupos de edades con mayor representación en la población masculina son los de 20 a 24 años con 176 individuos, que suponen el 30'14\%; el de 15 a 19 años con 140 individuos, el 23'97\%, y el de 10 a 14 años con 88 casos, un $15^{\prime} 07 \%$ del total de la muestra. Para la población femenina los grupos más representados son el de 20 a 24 años con 147 esclavas, el 31 '55\%; el de 15 a 19 años con 121, el 25'97\%, y el de 25 a 29 años con 70 , que representan el $15^{\prime} 02 \%$ del total de esclavas vendidas.

Las edades promedio de los esclavos vendidos en los siete primeros años que hemos estudiado, oscilan entre los 24 y los 28 años, excepto en 1585, año en el que el promedio de edad es de 22 años. A partir de 1590 la edad media de los esclavos disminuye y oscila entre los 19 y los 23 años (ver apéndice 1). La causa de esta disminución se explica por el hecho del aumento del número de cargazones llegadas en la década del 90, en las cuales arribaban esclavos jóvenes llevados a América directamente desde África.

10 Morineau, Michel: “Un siglo después de la conquista: los imperios ibéricos.” Leon, Pierre: Historia económica y social del mundo I. La apertura del mundo. Siglos XIV al XVI. Madrid, 1978, vols. III y IV, pág. 130.

11 Moreno Fraginals, Manuel: “Aportes culturales y deculturación”, en La historia como arma y otros estudios sobre esclavos, ingenios y plantaciones. Barcelona, 1983, pág. 30. 
La edad del esclavo influía decisivamente en su precio, pues ésta era un factor íntimamente relacionado con la productividad; una menor edad garantizaba la explotación del esclavo durante un mayor período de tiempo, lo que representaba más productividad y mayor rentabilidad.

Los esclavos de ambos sexos que alcanzaban mayor precio eran los que se encontraban entre los 20 y los 40 años, fuera de este intervalo, tanto más jóvenes como más viejos, sus precios eran menores. El límite de 15-20 años era el mínimo generalmente para los importados pues, "traerlos más jóvenes implicaba tener un "activo" (en el sentido contable) de baja productividad y, sin embargo, corriendo los mismos riesgos de muerte de los altamente productivos". ${ }^{12}$

Los cálculos de correlación nos revelaron las edades en las cuales los esclavos alcanzaban un mayor precio a lo largo del período estudiado; estas edades oscilan entre los 23 y los 31 años.

Este análisis fue realizado también para las poblaciones masculina y femenina por separado y demostró que hasta los diez años los hombres eran más caros que las mujeres pero a partir de esta edad en la generalidad de los casos el precio de las mujeres estuvo por encima.

No obstante no podemos ceñir la realidad a los marcos estrechos de los cálculos matemáticos, pues en la muestra abundan casos que se salen de estos estimados, y pudiéramos citar varios ejemplos de compraventa de esclavos en edades óptimas con precios mínimos o, por lo contrario, esclavos muy jóvenes y muy viejos vendidos a precios superiores a los considerados lógicos por los cálculos.

En estos casos excepcionales hay que entrar a analizar particularmente las posibles condicionantes que actuaron en estas operaciones, que pudieran estar dadas por el conocimiento de un oficio por parte del esclavo, o un estado de salud deplorable, por ejemplo, lo que nos sirve para entender los resultados no del todo afirmativos de los cálculos matemáticos.

\section{La influencia del sexo en el precio de los esclavos}

En la muestra analizada aparecen un total de 584 esclavos hombres y 466 mujeres, con una edad promedio de $21^{\prime} 8$ y 21 respectivamente y un precio medio para los hombres de $232^{\prime} 85$ ducados y de 243 '68 ducados para las mujeres.

12 Ibídem, pág. 29. 
PROMEDIOS DE EDAD Y PRECIO, PRECIO MÍNIMO Y MÁXIMO POR SEXOS

N. Prom. edad Prom. precio Precio mín. Precio máx.

\begin{tabular}{llllll}
\hline Hombres & 584 & $21^{\prime} 8$ & $232^{\prime} 85$ & 50 & 470 \\
Mujeres & 466 & 21 & $243^{\prime} 68$ & 50 & 400
\end{tabular}

Se señala que durante todo el período de la trata se introdujeron en América una mayor cantidad de esclavos hombres que de mujeres; este predominio de la importación de hombres se debía a factores económicos, pues la mujer esclava siempre fue considerada como de baja productividad en comparación con el hombre.

En nuestra muestra, que por supuesto no refleja todo el proceso introductor, sino sólo un grupo de operaciones del mercado habanero, se observa anualmente una mayor cantidad de compra de hombres que de mujeres, pero la diferencia de estas cantidades es generalmente mínima, y en los años 1592 y 1596 contamos con una mayor cantidad de ventas de esclavas que de esclavos (ver apéndice 2).

Un aspecto a tener en cuenta para explicarnos este casi logrado equilibrio entre sexos está determinado por el tipo de producciones a las que estaban destinados generalmente los esclavos de particulares en La Habana de esos años, es decir, pastoreo de ganado mayor y menor, cría de aves y labranza de estancias destinadas en su mayoría al consumo local, servidumbre, y en el caso de esclavos conocedores de oficios era habitual su alquiler.

En todas estas tareas podían resultar útiles ambos sexos, e incluso las esclavas eran alquiladas como criadas, cocineras y lavanderas, con mucha mayor frecuencia que los esclavos; también se plantea por algunos historiadores el hecho de que eran prostituidas por sus dueños, cosa de la cual no tenemos ninguna evidencia, pero que tampoco se puede descartar.

En el período de nuestro interés se da un fenómeno harto curioso que debemos tener en cuenta en nuestro análisis, que es el hecho de que la venta de esclavas resultaba más lucrativa para los cargadores que la de los esclavos, en tanto aquéllas se compraban a un precio bastante inferior al de los hombres en África y se vendían en América a precios no muy diferentes que el de éstos.

El precio promedio de los esclavos varones se mantiene en la mayor parte de los años analizados por encima de los 200 ducados, excepto en 
1585 , con 194 ' 90 ducados, y 1587 , con 194'95 ducados. Los precios promedio de las esclavas estuvieron igualmente por encima de los 200 ducados en la mayor parte de los años, con excepción de 1585 y 1586, que fueron de 167 ducados y 196' 66 ducados.

Al comparar los precios medios anuales alcanzados por los esclavos a lo largo del período, salta a la vista el hecho de que el precio promedio de los hombres supera al de las mujeres sólo en cinco años: 1585, 1586, 1589, 1590 y 1593 (ver apéndice 2).

Esto nos indica que generalmente las esclavas fueron en el período más caras que los esclavos; el motivo de este mayor precio debe estar dado por la condición propia de la mujer de reproducir la fuerza de trabajo, lo cual pudiera indicar que en los años de nuestro estudio resultaba más económico para la mayoría de los habitantes de la Ciudad mantener a una esclava y a sus hijos, que comprar un esclavo en el mercado, ya que debido a la alta demanda, la poca oferta y los altos precios, comprar un esclavo en La Habana de la época, era uno de los mayores gastos que debía encarar cualquier vecino.

Un esclavo en estos años solía ser más caro que muchas de las parcelas de tierra que se vendían en el territorio occidental de la Isla, o que ciertos tipos de embarcaciones que fondearon en el puerto habanero, o que algunos de los solares urbanos que se traspasaron en la villa y también semejantes en precio al alquiler anual de algunas de las pocas casas en buenas condiciones de la ciudad.

En el precio de determinadas esclavas se incluía el de sus hijos pequeños en el caso que los tuvieran, algo muy habitual y que tenía una clara motivación mercantil, en tanto encarecía el precio de la madre y no se pagaban por ellos los impuestos establecidos.

$\mathrm{Al}$ observar el fenómeno del precio de los esclavos de nuestra muestra, una vez dividida la población por sexos, se hace posible apreciar el hecho de que las mujeres esclavas resultaban generalmente más caras que los hombres, rasgo que también se hará evidente en el análisis de los precios por sexo según el origen del cautivo.

No obstante nos negamos a dar a esta conclusión una importancia trascendental, pues esta diferencia de precios no es tan relevante; mas bien lo característico del período es una similitud de los precios entre ambos sexos, ya que comúnmente podemos encontrar operaciones en todos los años analizados en que se pagan iguales precios, bajos o muy altos, por individuos hombres y mujeres. 


\section{El precio de los esclavos con oficios y su alquiler}

El caso del contrato de aprendizaje concertado entre Juan Recio y el sastre estante en la Villa, Luis Gálvez, el día 1 de septiembre de 1586, para que enseñara a su esclavo Nicolás el oficio en espacio de un año, nos adentra en otro de los aspectos a tener en cuenta al estudiar el comportamiento del precio de los esclavos en el período en cuestión, que es el aumento del valor de uso y por ende del precio del esclavo, en la medida de que era capaz de desempeñar un oficio.

Recio debía garantizar, por todos los medios, la permanencia del esclavo en poder del maestro y se comprometía a no retirárselo, so pena de pagarle "lo que juzgare un oficial que merece de jornal el dicho negro hasta ser cumplido el dicho año"; por su parte Gálvez debería vestir, calzar y alimentar al esclavo, tratarle bien y mantenerle en su casa "... y le mostraré el dicho oficio de sastre sin encubierta... y si por mi culpa o negligencia dexare de aprender el dicho oficio, hasta que lo sepa lo tendré en mi casa y le pagaré lo que comúnmente un oficial... ganare en aquella sazón.”.13

La costumbre de alquilar a los esclavos, estuvo bastante generalizada en la sociedad colonial cubana, y se circunscribió generalmente a las ciudades hasta el siglo XIX. ${ }^{14}$ En el período que estudiamos, los dueños de esclavos los alquilaban por un día, por uno o varios meses y hasta por tiempo de unos años; según el doctor Leví Marrero, cuando el alquiler se efectuaba por un tiempo relativamente largo, que podía ser de varios meses o un año, su precio era frecuentemente superior al salario de muchos trabajadores libres horros, indios e incluso españoles. ${ }^{15}$

Una ordenanza del 9 de junio de 1561 prohibía a los habaneros mandar a sus esclavos a ganar de por sí, quien lo hiciera se exponía a pagar una

13 Rojas: Indice... T. II, pág. 226.

14 Moreno Fraginals, Manuel: El ingenio. La Habana, 1986, T. I, pág. 291.

15 Marrero, Leví: Cuba: economía y sociedad. Siglo XVI: la economía. Madrid, 1974, T. II, pág. 366. Al analizar el tema de los derechos reales en su obra, Marrero, en el capítulo noveno referente a la sociedad cubana en el siglo XVI, concretamente en el apartado dedicado a los esclavos, aborda algunos aspectos relacionados con el fenómeno esclavista, cuando se refiere a las distintas modalidades del trabajo que estos desempeñaban y las condiciones de vida de los mismos. Es en esta sección donde aborda brevemente la cuestión del precio de los esclavos en La Habana, basado fundamentalmente en las transcripciones de María Teresa de Rojas que abarcan la década entre 1578 y 1588, enriqueciendo este aspecto con información sobre las disposiciones reales que regulaban este comercio, sobre las formalidades y generalidades del mismo y sobre la procedencia de los esclavos. 
multa de 3 ducados y al esclavo se le darían 100 azotes. En la orden, por lo contrario, se incentivaba el hábito de alquilarlos. ${ }^{16}$

Tal anuencia de las autoridades estaba motivada por dos razones que hacían del alquiler de esclavos algo conveniente. La primera era que las autoridades se servían de los esclavos que alquilaban a los vecinos para realizar determinadas obras de interés en la villa para las que no contaban con mano de obra, tales como la construcción de la iglesia, el acarreamiento de mercancías y las obras de la zanja; incluso fue habitual también la presencia de esclavos alquilados en las obras de fortificación.

La segunda estaba relacionada con el cobro que se hacía por el derecho de alquilar esclavos a los propietarios que no eran vecinos de la Ciudad. Este cobro fue establecido en la sesión del Cabildo del 21 de octubre de 1569 , y respondía a las quejas de los residentes habaneros que veían con desagrado que los de tierra adentro se beneficiaran alquilando a sus esclavos en la villa, mientras que no pagaban ninguna de las contribuciones ni prestaban los mismos servicios propios de los vecinos.

Por ello el Cabildo estableció que los no residentes que quisieran alquilar sus esclavos en la ciudad, tuvieran que contribuir en todo lo que era costumbre en La Habana de esos años, como medio vecino si tenían un esclavo alquilado en la villa y como un vecino normal, si eran dos los esclavos ganando jornal. ${ }^{17}$

A pesar de las prohibiciones, los vecinos habaneros continuaron mandando a sus esclavos a ganar por su propia cuenta en vez de establecer contratos de alquiler, y en el año 1589 la situación ya era de desorden generalizado, según las autoridades del Cabildo, las que subieron la multa a 6 ducados e incentivaron la denuncia con un interés monetario. ${ }^{18}$

El alquilar esclavos fue habitual entre los dueños de pocos esclavos, uno o dos de ellos, quienes tenían en esta actividad una de las formas de obtención de entrada monetaria ${ }^{19} \sin$ embargo, es posible encontrar testimonios de cuando lo hicieron algunos de los elementos del grupo de poder habanero, muchos de ellos los mayores propietarios de esclavos de la ciudad.

16 Roig de Leuchsenring, Emilio: Actas capitulares del Ayuntamiento de La Habana 15661574. La Habana, 1933, T. II, pág. 76.

17 Ibídem, págs. 164-165.

18 Archivo del Museo de la Ciudad de La Habana (AMCH), Actas capitulares del Ayuntamiento de La Habana, acta del 11 de noviembre de 1589, transcripción pág. 287.

19 Le Riverend Brusone, Julio: Historia económica de Cuba. La Habana, 1967, pág. 84. 
El alquiler de esclavos estuvo relacionado con la usura y representaba para su dueño la entrada de una suma de dinero efectivo en un momento en el que lo necesitaba. En varias ocasiones los propietarios del esclavo recibían una suma de dinero mayor de la que costaba el trabajo del esclavo que daban en alquiler y se comprometían en la escritura a devolver el resto al finalizar el tiempo del contrato. ${ }^{20}$

La operación realizada entre Francisca de Orellana y el capitán Francisco de Rojas, pudiera tratarse de un préstamo encubierto, no sabemos por cuáles motivos y con qué tanto por ciento de interés. La mencionada Francisca le alquiló al capitán una esclava, durante seis meses cobrándole un real diario, lo que sería aproximadamente 180 reales (16,36 ducados) por todo ese tiempo; sin embargo, acto seguido Francisca le pagó 100 ducados por adelantado, lo que no tiene mayor explicación en el documento y nos pudiera enfrentar a un caso de usura. ${ }^{21}$

Llama la atención la acción, reflejada en varios contratos, de alquilar esclavas acabadas de parir para que criaran a recién nacidos esclavos por espacio de un año y en tales casos la crianza incluía el amamantar al pequeño en los primeros meses de su vida.

Tanto los esclavos que se alquilaban como los que ganaban de por sí, obtenían ganancias propias que les permitían pagarles a sus dueños las cantidades por ellos exigidas y en muchos casos les posibilitaba la compra de su libertad; en esto lógicamente destacaron los esclavos que conocían un oficio.

Una idea bastante clara sobre la rentabilidad del alquiler de esclavos en la fecha, nos la pueden dar los cálculos sobre el tiempo en que tardaba un comprador en amortizar el precio del esclavo dándolo en alquiler. Para ello hemos estudiado algunos casos de varios años, tomando el promedio de precio anual por sexos como base del análisis.

El resultado nos deja claramente demostrado que el pago por los alquileres de los esclavos hacía la actividad lo suficientemente rentable como para que se mantuviera a lo largo de todo el período estudiado, pues se podía recuperar lo pagado por uno de ellos en un tiempo que iba entre los dos y los cinco años, lo que daba un amplio margen de rentabilidad si se entiende que los esclavistas esperaban que los esclavos jóvenes tuvieran una vida útil de 20 años aproximadamente como mínimo.

20 ANC, Regueyra, 1598, f. 569r. Un ejemplo de ello es el contrato de alquiler de una esclava fijado entre María Rodríguez, mujer de Melchor Rodríguez, y Felipa de Espinosa.

21 Ibídem, 1600, fols. 1005v-1006v. 
El trabajo de los esclavos con oficio estaba presente en la mayor parte del quehacer económico habanero; quiere esto decir que hubo presencia esclava en las labores de construcción llevadas a cabo en la Ciudad, los casos más representativos quizás estuvieran entre los esclavos del rey que trabajaron en la construcción de las fortalezas, muchos de los cuales aprendieron el oficio de la cantería, lo que le permitió a Gabriel de Montalvo, por poner un ejemplo ilustrativo, prescindir del trabajo de diez oficiales canteros a los que se les pagaba jornal y sustituirlos por ocho esclavos del rey que eran tan diestros como los anteriores en las tareas propias del oficio..$^{22}$

También muchos esclavos estuvieron vinculados a la ganadería como criadores y vaqueros; entre las mujeres fueron comunes las cocineras, las hospederas, las lavanderas y las vendedoras; también hubo esclavos dedicados a la sastrería, la tenería, aserradores; incluso contamos con un ejemplo de un esclavo conocedor del oficio de calafate, actividad mucho menos propia de los hombres de esta condición.

Tal es el caso del esclavo Pedro, de 36 años y de confusa nación, ya que fue vendido dos veces a lo largo del año 1599, conjuntamente con su mujer, siendo presentado la primera vez como congo y la segunda como angola. El precio de ambos esclavos varió de enero a octubre del mencionado año en 10 ducados, ya que el 12 de enero el capitán Tomás Bernardo de Quirós, vecino y regidor de la Ciudad, los vendió al capitán Pedro de Caravajal, también vecino, por 730 ducados, mientras que éste los dio a Francisco Núñez el 30 de octubre, por la cifra de 720 ducados..$^{23}$

$\mathrm{Al}$ dividir la cifra total del precio de la pareja, nos da un alto precio individual para ambos esclavos: 360 ducados por cada uno, que supera en aproximadamente 100 ducados los precios promedios calculados en la muestra para ese año, tanto en la población masculina (256'7 ducados) como en la femenina (260'42 ducados). Debemos tener en cuenta además que estos precios promedios serían los más adecuados para esclavos entre los 20 y los 25 años, o sea 10 años más jovenes que el citado esclavo; pero creo que sería ilógico pensar que costaran lo mismo un esclavo joven, conocedor del arte de la calafatería, y una esclava, que debió ser igualmente joven, pero de la que no se señala otra característica más de que es la esposa de Pedro.

Con ello quiero decir que el precio del mencionado esclavo lo podemos situar por encima de los 400 ducados sin temor a equivocarnos, máxi-

22 AGI, Santo Domingo, 99, r. 13, n. ${ }^{\circ}$ 54. Gabriel de Montalvo a S.M., 15 de enero de 1577.

23 ANC, Regueyra, 1599, transcripción, T. I, pág. 47, T. II, pág. 275. 
me cuando lo sabemos conocedor de uno de los oficios más necesarios en La Habana del siglo XVI, dedicada a la construcción de naves en sus astilleros con el interés de la Corona de por medio, y en la que sabemos por varios documentos que no abundaban los conocedores del oficio en cuestión.

En el año 1582 en La Habana sólo había dos vecinos y dos estantes conocedores del oficio de calafate. ${ }^{24}$ En el mes de marzo del año 1591, en pleno apogeo de la actividad de construcción naval habanera - una real cédula de 1589 había establecido que se fabricaran entre 12 y 18 fragatas en los astilleros habaneros- sólo estaban radicados en La Habana el maestro del astillero y "cinco o seis carpinteros", frase literal del gobernador y posiblemente imprecisa en cuanto a la cifra, pero de innegable veracidad, pues le urgía conocer las últimas ordenes del rey al respecto de las fragatas para tomar 40 carpinteros y algunos calafates de las flotas antes de que partieran del puerto con destino a la Península. ${ }^{25}$

No contamos hasta el momento con el conocimiento exacto del salario de un calafate en el año 1599, la única información que podemos brindar es la que ofrece Leví Marrero para el año 1579 en su obra, donde señala como paga anual de un calafate la cifra de 142000 maravedíes, es decir, 369,67 ducados anuales, ${ }^{26}$ un alto salario que posiblemente no se le pagara a un esclavo, pero debemos ubicar muy cercanas a esa cifra las posibles ganancias del propietario de un calafate si lo daba en alquiler, como es de suponer que haría.

Finalizando debemos plantear que uno de los mayores incentivos de la enseñanza de un oficio a un esclavo era el hecho, demostrado por los historiadores Leví Marrero y Julio Le Riverend, de que en La Habana el precio de un esclavo oficial se duplicaba en el momento en que se hallaba surta la flota en el puerto, cosa que ocurría anualmente durante varios meses incluso. ${ }^{27}$

\section{La procedencia de los esclavos y su precio}

Según Fernando Ortiz, las leyes establecieron que sólo podían ser llevados a América esclavos de las zonas de Angola, Guinea, Cabo Verde y las islas cercanas, mas el comercio tratista obvió todas las disposiciones

\footnotetext{
24 Marrero: Cuba: economía..., pág. 338.

25 AGI, Santo Domingo, 99, r. 16, n. ${ }^{\circ}$ 148. Juan de Tejeda a S.M., 29 de marzo de 1591.

26 Marrero: Cuba: economía..., pág. 205.

27 Ibídem, pág. 84; Le Riverend: Historia económica..., pág. 123.
} 
y se condujeron al nuevo Mundo esclavos de todas las regiones de África occidental y hasta de la oriental..$^{28}$

Los africanos eran designados en muchos casos por la etnia a la cual pertenecían, en otros por la región geográfica de la cual procedían y algunos lo fueron por el nombre de la factoría por la cual eran sacados del continente; siendo la procedencia de los esclavos otro de los elementos que podía influir en el precio de estos, ya que los compradores rápidamente llegaron a preferir determinadas condiciones de unas naciones sobre las de otras.

En la actualidad es complicado conocer el verdadero origen de los llegados a América, pues se le dieron nombres que tendían a generalizar, comprendiendo bajo la denominación de una gran zona a hombres y mujeres procedentes de tribus y etnias diferentes.

Los esclavistas habaneros preferían a mediados del siglo a los esclavos biáfaras y bran, considerados buenos trabajadores, según deja ver la petición que hacen los oficiales reales de la Isla de que se introdujeran esclavos de esas etnias; igualmente reconocían la calidad de los esclavos procedentes de la zona de Cabo Verde, que fueron en un período los esclavos que más caros se podían vender en el América, según establecía la real provisión de 6 de junio de 1556, que regulaba las ventas. ${ }^{29}$

Se ha determinado que entre los años 1570 y 1595, período de excesiva escasez de esclavos en la Isla, las regiones de Senegambia y Sierra Leona fueron las principales suministradoras de los que se encontraban en manos de los vecinos habaneros, situación que cambió radicalmente a partir de la firma del asiento con Pedro Gómez Reynel y la etapa de suministro portugués de esclavos a toda la América hispana, en la que por cuestiones de rivalidad entre Portugal y otras naciones europeas, dirigieron sus intereses y mecanismos tratistas hacia la zona de Angola, y por ende América, y La Habana en particular comenzó a contar con una mayor cantidad de esclavos de esta procedencia a partir de $1595 .{ }^{30}$

28 Ortiz, Fernando: Los negros esclavos. La Habana, 1975, pág. 40.

29 Fuente García, Alejandro de la: "Los esclavos africanos en La Habana: Zonas de procedencia y denominaciones étnicas, 1570-1699”, Revista Española de Antropología Americana, n. ${ }^{\circ} 20$, Madrid, 1990, pág. 148. Alejandro de la Fuente ha abordado recientemente en varios artículos el análisis de algunos de los aspectos relacionados con el mercado esclavista en los siglos XVI y XVII, basándose, entre otras fuentes, en los protocolos notariales habaneros. Este historiador cubano cuenta en la actualidad con tres esclarecedores artículos publicados en revistas cubanas y extranjeras, donde trata los temas de la introducción de esclavos, sus matrimonios, sus zonas de procedencia y denominaciones étnicas.

30 Ibídem, pág. 158. 
Los esclavos calificados como Angola son el grupo más representado en nuestra muestra, con un total de 402 individuos y una edad promedio de 20 años. Las cifras demuestran la primacía en la introducción y venta de esclavos angola por encima de los de otras procedencias.

Estos esclavos procedían de la zona comprendida entre los ríos Dande y Kwanza, que era la conocida en la época como Angola, y según el análisis de la muestra realizado por el historiador Alejandro de la Fuente, fueron minoría entre los esclavos llegados a Cuba entre los años 1585 y 1594, pero ya a partir de 1595, año en que se inicia el denominado período portugués de la trata, fueron la mayoría de los llegados a la Isla hasta mediados del siglo XVII. ${ }^{31}$

El precio promedio calculado para los esclavos angola en el período es de 232'27 ducados aunque los esclavos así denominados llegaron a tener precios de hasta 400 ducados. De estos esclavos 198 eran hombres y 204 mujeres, con precios promedio de 227'59 ducados y 236' 81 ducados respectivamente.

Los esclavos bran, procedentes del interior de Costa de Oro y extraídos del continente africano a través de la factoría Elmina, ubicada entre los ríos de Sierra Leona y el Volta, hacen un total de 83 individuos en la muestra con una edad promedio de 23 años. Los bran alcanzaron un precio promedio en el período de 254 '86 ducados, pagándose un precio máximo de 390 ducados por un esclavo de esta procedencia. Se comerciaron 42 hombres y 41 mujeres bran, con una edad promedio para los primeros de 22 años y para las mujeres de 24; el precio promedio de estas últimas fue de 262'05 ducados y para los hombres de 247'83 ducados.

Procedentes de la región llamada Río Grande en Senegambia, los biáfara aparecen con una frecuencia de 78 individuos. El precio promedio en el que se vendieron los biáfara fue de $263^{\prime} 45$ ducados, los hombres en $255^{\prime} 14$ y las mujeres en 273 ' 66 ducados.

Los esclavos calificados como congos incluían a miembros de numerosas tribus de la zona que se incluyeron en la trata bajo esa denominación general, como es el caso de los anchico; ${ }^{32}$ éstos ascienden a 89, fueron vendidos a un precio promedio de 232'97 ducados; los hombres a $228^{\prime} 83$ y las mujeres en 242' 13 ducados.

Los esclavos criollos vendidos aparecen con una frecuencia de 54 casos, con un precio promedio de 233 ' 50 ducados. Los hombres en 230 ' 86 ducados y las mujeres en 236'35 ducados.

31 Ibídem, pág. 153.

32 En la muestra hay 12 casos de esclavos anchicos. 
Otro grupo importante en nuestra muestra es el de los zape, procedentes de la región de Sierra Leona, los que aparecen con una frecuencia de 33 casos. El precio promedio calculado para estos esclavos es de $267^{\prime} 48$ ducados, para los hombres de 259'26 y para las mujeres de 278'64 ducados..$^{33}$

Además de los lugares de origen de los esclavos anteriormente mencionados, también se vendieron esclavos mandingas, procedentes de las márgenes del río Gambia (17 casos), los biohos, habitantes del archipiélago de Bissagos (14 casos), banón, bañón o bañol, procedentes de las riberas del Cazamancia ( 25 casos), nalúes, procedentes de la región entre los ríos Geba y Núñez (9 casos) y jolofos, ubicados entre los ríos Senegal y Gambia (13 casos); estos últimos esclavos tenían fama de ser rebeldes y por ello una real cédula de 28 de septiembre de 1532 había prohibido su introducción, pero se continuó llevándolos a lo largo de todo el siglo XVI. ${ }^{34}$

Con menor frecuencia aparecen en la muestra analizada esclavos de otras etnias y procedencias, tales como los basambo; los arará, procedentes de la zona de Dahomey; los berbesí, propios de la región circundante al río Salum, en Senegambia; los carabalí, procedentes de la zona del Golfo de Guinea y que rápidamente gozaron de preferencia entre los esclavistas por su buena actitud hacia el trabajo; los embo; los folupos, que habitaban en las márgenes del río Cazamancia; los lucumí, procedentes del reino de Ulcami; los macambi; los volante y los papei, que habitaban en la desembocadura del río Santo Domingo, donde los portugueses establecieron la factoría Cacheu ${ }^{35}$ Así como en menor medida individuos de zonas, de los que no se citó en el momento de la venta su denominación étnica. Es decir, en la muestra contamos con algunos casos de esclavos de Cabo Verde; de Guinea, considerados altamente rentables y que gozaban de aceptación por los habaneros, según nos deja ver la real cédula de 6 de junio de 1556 fijando un precio máximo de los esclavos en 100 ducados y que exceptuaba a los de Guinea, poniéndoles un sobreprecio de 20 ducados por sus mejores condiciones; de Mozambique, Sao Tomé, Zambia. También hay unos pocos casos de esclavos de Terranova; este nombre responde al de la factoría portuguesa en la cual fueron comprados, Porto Novo, ubicada en el golfo de Guinea.

33 El apéndice 3 muestra la información de los precios promedio calculados para los esclavos según su procedencia geográfica o étnica, una vez dividida la población por sexos.

34 Fuente García: “Los esclavos africanos en...”, págs. 138, 140 y 142.

35 Ibídem, págs. 139, 143-144. 
Estuvieron presentes en el mercado habanero esclavos nacidos en la Península Ibérica y en tierras de América, a los cuales se les denominaba criollos. En nuestro trabajo los hemos nombrado criollos extranjeros para diferenciarlos de los nacidos en Cuba. De estos tenemos criollos de Portugal, de Sevilla, de Cartagena, de Jamaica, de Honduras, de Santo Domingo, de Popayán, etc.

Los esclavos nalú resultaron tener, según los cálculos, el precio promedio más elevado, que ascendió a 268'78 ducados; sin embargo, ningún esclavo nalú llegó a tener un precio máximo de 400 ducados, como en el caso de los esclavos de Angola, del Congo, los biáfara, los zapes y algunos criollos nacidos en América.

Según nuestras fuentes los angola, a pesar de gozar de una buena aceptación por los esclavistas habaneros, tuvieron un menor precio que los esclavos con otros orígenes. Este grupo cuenta con el menor precio promedio calculado: 232'27 ducados. De ellos se planteaba que eran robustos, dóciles y hábiles para el trabajo, lo cual, combinado con un precio módico, los hacía gozar de gran aceptación. Debemos acotar que, no obstante tener estos esclavos el menor precio promedio, los hubo con tan buenas condiciones que llegaron a costar 400 ducados, lo que significaba un precio bastante elevado para la época.

En general los esclavos llegaban al mercado precedidos de criterios sobre su productividad, carácter e idoneidad para los distintos trabajos; es por ello que se consideraba, por ejemplo, que los biáfara y los bran eran buenos trabajadores y que los mandinga eran esclavos de poco trabajo.

No obstante, la conclusión a que se arriba después de todo este análisis es que no había una gran diferencia entre los precios de los esclavos de distinta procedencia; más bien se puede señalar que esta característica no era una de las que más podía influir en el precio de la "mercancía" esclavo, máxime cuando no fue frecuente la llegada de partidas y cargazones a la bahía habanera en esos años, por lo que los compradores se debieron conformar con lo ofertado por los vendedores, entiéndase angolas.

$\mathrm{Al}$ comparar los promedios de precio calculados para cada una de las procedencias estudiadas, se observa que la generalidad de estos esclavos se vendía a precios bastante semejantes y que la diferencia no llegó a ser nunca muy señalada y rondó sólamente en estos años, entre los 25 y los 30 ducados.

Al observar las cifras de precios se hace de nuevo evidente el mayor valor que tenían las esclavas sobre los esclavos; en todas las etnias el pre- 
cio promedio de las mujeres es mayor que el de los hombres; en relación con los precios máximos igualmente ocurre que las esclavas angola, congas, biáfaras y criollas extranjeras llegaron a costar hasta 400 ducados, un precio que sólo alcanzaron los hombres de la etnia zape (ver apéndice 3).

\section{Conclusiones}

Una vez vistas las distintas variables que se han considerado como fundamentales para la compresión del comportamiento del precio de los esclavos, podemos decir que nuestro estudio evidencia un aumento del valor de esta variable a lo largo del período pero con continuas oscilaciones; además este análisis permite pronosticar un descenso del precio de los esclavos para los años siguientes a 1600, si tenemos en cuenta la línea de tendencia observada, que se muestra en el gráfico.

\section{SERIE CRONOLÓGICA DE LOS PRECIOS PROMEDIO}

DE LOS ESCLAVOS DE LA MUESTRA (1579-1600)

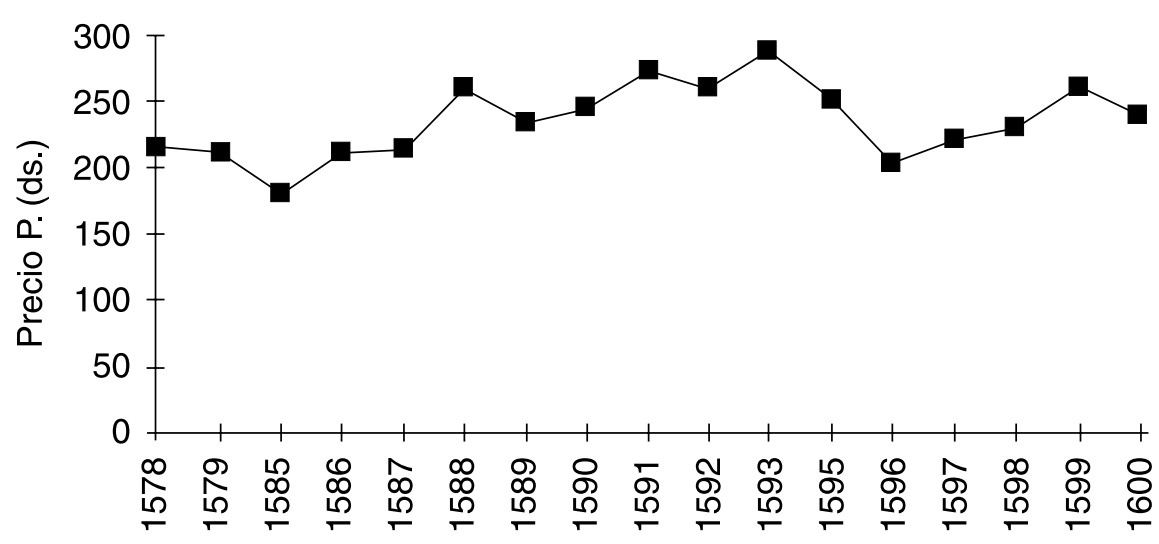

Años

A su vez los índices relativos de precio calculados demuestran igualmente el aumento del precio de la pieza de esclavo desde los años iniciales del período estudiado hasta 1600, evidenciando también los momentos en que esta mercancía alcanzó su mayor valor real, léase años 1593, 1591 
y 1599 y los años en que tuvo las cotas menores el precio de un esclavo en el mercado habanero, es decir, los años 1579,1585 y $1596 .{ }^{36}$

$\mathrm{Al}$ relacionar las cifras de esclavos vendidos anualmente en nuestra muestra con los precios promedio calculados para cada año se concluye que, paralelamente al ascenso paulatino del número de esclavos vendidos, se produce un aumento del precio de los mismos, lo que nos hace pensar en el hecho de que nunca la llegada de una mayor cantidad de esclavos fue un factor que influyese en el precio de los mismos disminuyendo este valor.

El ascenso del precio de los esclavos fue constante en el período y las disminuciones en el mismo estuvieron condicionadas por factores propios de este comercio, fundamentalmente la condición física de los esclavos, lo que explica el fenómeno del año 1596 por ejemplo, en el que a pesar de ser considerable la cifra de bozales entrados, el promedio de precio disminuye por la pésima condición física de la mayor parte de los esclavos llegados directamente desde África.

En cuanto a las posibles variables que podían influir en el precio de un esclavo en el momento de su venta, es necesario plantear que, si bien el sexo y la procedencia eran tenidos en cuenta para fijar un precio en la operación, estos elementos no determinaban una gran diferencia de valor, sino que más bien lo normal era que hubiera una mínima o ninguna variación, entre lo que se pagaba por un hombre y una mujer con similares condiciones físicas, o entre un angola y un bañón con iguales aptitudes, por citar dos ejemplos.

Ahora bien, guiados por los cálculos matemáticos se nos hizo evidente que no era sólo la edad la que influía en el precio del esclavo; si bien es cierto que esta es una de las variables fundamentales que decidían el precio de un esclavo, la relativa y no total correspondencia entre edad y precio se explica por la influencia que ejercía en la condición corporal del esclavo en la operación.

Es lógico que dentro de la población esclava en venta fueran mayoría los jóvenes de determinadas edades propias para el trabajo físico a mediano y largo plazo (10, 15 e incluso 20 años a partir del momento de la compra), pero ya una vez situada "la pieza" dentro de esos parámetros ocurría que no todos tenían las mismas condiciones físicas, siendo esta la variable determinante para la fijación de un precio por parte del vendedor y el pago de tal cantidad por el comprador.

36 Los índices relativos de precio se calcularon tomando como año base el 1589 por ser el que contaba con un precio promedio más representativo y con una cantidad de esclavos vendidos más cercana a la media de todos los años. 
La posesión de esclavos no sólo reportaba el beneficio de utilizar su fuerza de trabajo en una actividad económica específica, sino que además daba al dueño la posibilidad de utilizarlos como valor de cambio, según dejan ver las fuentes en varios casos de hipotecas, empeños, trueques, imposiciones de censo, donaciones en dote, etc. También los esclavos podían ser generadores de capital para unos y único medio de mantenimiento de otros, en tanto se hizo común en la Ciudad el darlos en alquiler o mandarlos a trabajar por cuenta propia, de tal forma que algunos habaneros los hicieron aprender un oficio, siendo en estos casos particulares la condición de oficial del cautivo, la principal cuestión a tener en cuenta en caso de venta. 



\section{Apéndice 1}

CANTIDADES DE OPERACIONES REALIZADAS Y DE ESCLAVOS VENDIDOS ANUALMENTE CON LOS PROMEDIOS DE EDAD Y PRECIO

\begin{tabular}{|c|c|c|c|c|}
\hline Año & N. operaciones & N. esclavos & P. edad & P. precio $(d s)$ \\
\hline 1578 & 4 & 4 & 28 & $215^{\prime} 75$ \\
\hline 1579 & 23 & 25 & 27 & $210^{\prime} 2$ \\
\hline 1585 & 16 & 20 & 22 & $180 ’ 95$ \\
\hline 1586 & 16 & 16 & 24 & $211^{\prime} 93$ \\
\hline 1587 & 28 & 38 & 24 & $212^{\prime} 74$ \\
\hline 1588 & 25 & 27 & 25 & $257^{\prime} 5$ \\
\hline 1589 & 56 & 68 & 25 & $231^{\prime} 4$ \\
\hline 1590 & 42 & 50 & 20 & $243 ’ 84$ \\
\hline 1591 & 67 & 78 & 21 & $270 ’ 34$ \\
\hline 1592 & 51 & 60 & 22 & $258^{\prime} 68$ \\
\hline 1593 & 12 & 14 & 22 & $286^{\prime} 46$ \\
\hline 1595 & 102 & 177 & 19 & $250 ’ 05$ \\
\hline 1596 & 77 & 123 & 20 & $202 ’ 98$ \\
\hline 1597 & 36 & 42 & 22 & $218^{\prime} 61$ \\
\hline 1598 & 65 & 71 & 23 & 229 \\
\hline 1599 & 108 & 121 & 22 & $258^{\prime} 53$ \\
\hline 1600 & 152 & 204 & 19 & $236^{\prime} 63$ \\
\hline Total & 880 & 1.138 & 21 & $237^{\prime} 65$ \\
\hline
\end{tabular}

Fuentes: ANC, Escribanía de Regueyra, 1578-1579, 1585-1593, 1595-1600.

\section{Apéndice 2}

CANTIDADES DE ESCLAVOS VENDIDOS ANUALMENTE POR SEXO, CON LOS PROMEDIOS DE EDAD Y PRECIO (DS)

\begin{tabular}{|c|c|c|c|c|c|c|}
\hline \multirow[b]{2}{*}{$A \tilde{n} o$} & \multicolumn{3}{|c|}{ HOMBRES } & \multicolumn{3}{|c|}{ MUJERES } \\
\hline & $N$ & P. edad & P. precio & $N$ & P. edad & P. precio \\
\hline 1579 & 20 & 28 & $202 ’ 75$ & 5 & 27 & 240 \\
\hline 1585 & 10 & 21 & $194 ' 9$ & 10 & 24 & 167 \\
\hline 1586 & 8 & 30 & $223 ’ 38$ & 6 & 18 & $196^{\prime} 66$ \\
\hline 1587 & 20 & 25 & $194 ’ 95$ & 14 & 24 & $238^{\prime} 14$ \\
\hline 1588 & 18 & 25 & $240 ’ 3$ & 9 & 25 & $282 ’ 33$ \\
\hline 1589 & 32 & 25 & $232^{\prime} 84$ & 15 & 26 & $228^{\prime} 33$ \\
\hline 1590 & 24 & 21 & $247^{\prime} 29$ & 21 & 21 & $239 ’ 9$ \\
\hline 1591 & 44 & 22 & $263^{\prime} 84$ & 29 & 21 & $280^{\prime} 89$ \\
\hline 1592 & 26 & 23 & $252^{\prime} 61$ & 28 & 22 & $264^{\prime} 32$ \\
\hline 1593 & 7 & 22 & $309^{\prime} 57$ & 6 & 23 & $262 ’ 83$ \\
\hline 1595 & 84 & 20 & $245^{\prime} 33$ & 72 & 19 & $255^{\prime} 55$ \\
\hline 1596 & 26 & 20 & $200 ’ 77$ & 51 & 20 & $206 ’ 37$ \\
\hline 1597 & 21 & 22 & $211^{\prime} 9$ & 18 & 21 & $226^{\prime} 44$ \\
\hline 1598 & 33 & 24 & $222 ’ 21$ & 33 & 23 & $238^{\prime} 81$ \\
\hline 1599 & 58 & 24 & $256^{\prime} 7$ & 56 & 21 & $260 ’ 42$ \\
\hline 1600 & 106 & 19 & $230 ’ 69$ & 91 & 19 & $243^{\prime} 54$ \\
\hline
\end{tabular}

Fuentes: ANC, Escribanía de Regueyra, 1579, 1585-1593, 1595-1600. 


\section{MARCOS D. ARRIAGA MESA}

\section{Apéndice 3}

CANTIDADES DE ESCLAVOS SEGUN LA PROCEDENCIA, CON LOS PRECIOS PROMEDIO, MINIMO Y MAXIMO Y CON EL PROMEDIO DE EDAD

\begin{tabular}{lrccrc} 
Procedencia & $N$. & P. edad & P. precio(ds) & P. mín. & P. máx. \\
\hline Anchico & 12 & 19 & $239^{\prime} 67$ & 120 & 305 \\
Angola & 402 & 20 & $232^{\prime} 27$ & 70 & 400 \\
Bañón & 25 & 23 & $242^{\prime} 2$ & 140 & 320 \\
Biáfara & 78 & 23 & $263^{\prime} 45$ & 150 & 400 \\
Bioho & 14 & 20 & $273^{\prime} 5$ & 181 & 381 \\
Bran & 83 & 23 & $254^{\prime}, 86$ & 50 & 390 \\
Congo & 77 & 21 & $232^{\prime} 97$ & 50 & 400 \\
Criollos & 54 & 21 & $233^{\prime} 5$ & 50 & 363 \\
Criollos extrj. & 32 & 20 & $254^{\prime} 91$ & 60 & 400 \\
Jolofo & 13 & 29 & $2466^{\prime} 62$ & 90 & 340 \\
Mandinga & 17 & 26 & $237^{\prime} 71$ & 115 & 377 \\
Nalú & 9 & 25 & $268^{\prime} 78$ & 210 & 370 \\
Zape & 33 & 25 & $267^{\prime}, 48$ & 130 & 400 \\
Otros & 37 & 26 & $222^{\prime} 92$ & 80 & 330
\end{tabular}

Fuentes: ANC, Escribanía de Regueyra, 1578-1579, 1585-1593, 1595-1600. 